\title{
Identidades y ajuares en las necrópolis altomedievales. Estudios isotópicos del cementerio de San Martín de Dulantzi, Álava $\left(\right.$ siglos VI-X) ${ }^{1}$
}

\section{Identities and grave goods in early medieval necropoleis. Isotopes studies in the cemetery of San Martin of Dulantzi, Alava $\left(6^{\text {th }}-11^{\text {th }}\right.$ centuries $)$}

\author{
Juan Antonio Quirós Castillo \\ Universidad del País Vasco/Euskal Herriko Unibertsitatea \\ Miguel Loza Uriarte \\ Arqueólogo \\ Javier Niso Lorenzo \\ Arqueólogo
}

\section{RESUMEN}

En este artículo se presentan los resultados de los estudios isotópicos realizados sobre los restos antropológicos recuperados en la intervención arqueológica de carácter preventivo realizada en el yacimiento altomedieval de San Martín de Dulantzi (AlegríaDulantzi, Álava) por parte de la empresa Iterbide. El hallazgo de una serie de tumbas fechadas en los siglos VI y VII en el interior de una iglesia, algunas de las cuales dotadas de objetos de adorno personal, ha permitido analizar en términos críticos el estatus, los patrones alimentarios y la movilidad de estos individuos a partir del análisis de los isotopos y de los rituales funerarios. Más concretamente se ha podido observar que se trata de una sociedad local, con una escasa incidencia de inmigrantes, y que los objetos de adorno personal constituyen un marcador de estatus social en el seno de una comunidad que presenta niveles de vida homogéneos. Asimismo se discuten estos resultados en relación con otras fases de ocupación del yacimiento y en el contexto de otros estudios realizados en varios yacimientos europeos coetáneos.

\section{SUMMARY}

This paper presents the results of the isotopic studies made on the anthropological remains recovered in the archaeological

${ }^{1}$ Trabajo realizado en el marco del proyecto de investigación "Desigualdad en los paisajes medievales del norte peninsular", HUM2012-32514, de la actividad del "Grupo de Investigación en Patrimonio y Paisajes Culturales / Ondare eta Kultur Paisaietan Ikerketa Taldea" (IT315-10) financiado por el Gobierno Vasco y de la UFI 11/02 "Historia, Pensamiento y Cultura Material". Las observaciones de Carmine Lubritto, Luis Ángel Ortega, Maite Iris García, Alfonso Vigil-Escalera Guirado y los evaluadores anónimos han mejorado notablemente el texto y a ellos va nuestro agradecimiento excavation of the early medieval site of San Martín of Dulantzi (Alegría-Dulantzi, Álava), carried out by the archaeological company Iterbide. The discovery of a series of tombs dating in the $6^{\text {th }}$ and $7^{\text {th }}$ centuries inside a church, some of them containing grave goods, has enabled the analysis, in critical terms, of the status, the eating patterns and the mobility of these individuals through the analysis of the isotopes and the funerary rites. Specifically, it has been possible to observe that it is a local society, with a scarce impact of immigrants, and the personal ornaments constitute a social status marker inside a community with homogeneous lifestyle. Likewise, these results are discussed in the context of other studies conducted at several European sites of the same chronology.

PALABRAS CLAVES: Necrópolis, Alta Edad Media, Isótopos, identidades, paleodieta, movilidad.

KEY WORDS: Necropoleis, Early Medieval Ages, Isotopes, identities, paleodiet, mobility.

\section{INTRODUCCIÓN}

Un lector atento de los trabajos realizados en los últimos veinte años sobre las prácticas funerarias de los primeros siglos de la Alta Edad Media tendrá que constatar que, a pesar de tratarse de una temática tradicional sobre la que se ha fundado la Arqueología Medieval, su estudio ha conocido una notable renovación. Una vez superados los presupuestos del historicismo cultural -que identificaban a los pueblos como sujetos históricos, a determinados objetos 
como marcadores étnicos y a la migración como el principal motor del cambio histórico- el empuje del procesualismo y, sobre todo, del posprocesualismo ha sustituido el paradigma de la etnicidad por el de la identidad, especialmente en el ámbito anglosajón y de habla germana ${ }^{2}$. El estudio de los procesos de etnogénesis, las aportaciones de la antropología a la hora de explicar la noción de identidad en términos situacionales y la crítica de las fuentes textuales ha llevado a cuestionar el significado atribuido de forma previa a los rituales y a las prácticas funerarias altomedievales poniendo el acento sobre los procesos de construcción de identidades e interpretando los cementerios en términos de escenarios de competitividad social (Halsall 2009).

La creación de este nuevo paradigma se sitúa en el contexto de una profunda renovación de los estudios sobre el período comprendido entre el final del mundo romano y el inicio de la Edad Media, analizados desde hace unos años más en términos de transformación que de fractura a raíz de proyectos tan influyentes como The transformation of the Roman World (Pöhl 1998a). De hecho, algunos autores han llegado a relativizar (y en los casos más extremos a cuestionar) la importancia misma de las invasiones germánicas, consideradas con anterioridad como un verdadero motor histórico (Brather 2002; Halsall 2007). Y aunque la réplica a las posiciones de los autores negacionistas ha sido muy contundente e incluso visceral (p. ej. Ward Perkins 2005; Valenti 2009), son muchos los especialistas que defienden en la actualidad la necesidad de analizar el significado de la etnicidad altomedieval en el marco de los procesos de construcción de las identidades sociales y las estructuras políticas postimperiales (Curta 2007). Los estudios más detallados y exhaustivos, como los realizados por S. Hackenbeck en Baviera, han mostrado la multiplicidad de significados contextuales que han tenido los rituales y los objetos hallados en las tumbas, cuestionando definitivamente la lectura étnica clásica (Hackenbeck 2007: 25-26, 2011). Estas controversias están permitiendo, por lo tanto, repensar en términos teóricos los procesos de construcción del registro material y en términos críticos, los apriorismos con los cuáles se ha estudiado la Alta Edad Media y el fin del mundo romano.

\footnotetext{
${ }^{2}$ La bibliografía es abundantísima; sin ánimo de exhaustividad se pueden señalar entre los balances críticos más recientes los trabajos de Gilett 2006; Castellanos 2007: 42-52; Hakenbeck 2008; Heather 2010: 28-56; Hakenbeck 2011: 11-25; James 2011: 118-187. El trabajo de Fernández Götz y Ruiz Zapatero 2011 constituye una magnífica introducción en castellano al estado de los estudios de la arqueología de la etnicidad abarcando una cronología mucho más amplia de la tratada en este trabajo.
}

De forma paralela el extraordinario desarrollo que ha conocido la arqueología preventiva en los últimos dos decenios en varios sectores europeos ha permitido contar con nuevos conjuntos funerarios de los siglos V-VIII que han sido analizados con protocolos e instrumentos analíticos muy rigurosos e innovadores. En particular las aportaciones de la arqueobiología, la osteoarqueología, la arqueología molecular y la arqueología isotópica están siendo fundamentales para llevar a cabo un salto cualitativo significativo en el estudio de estos documentos arqueológicos. Y aunque aún carecemos de nuevas síntesis territoriales de un cierto alcance, en los últimos años se están densificando este tipo de estudios realizados tanto en los nuevos yacimientos excavados en estos años como en el análisis de intervenciones más antiguas (p. ej. Carver 2009).

Este cuadro expuesto de forma extremadamente sintético contrasta notablemente con el estado de los estudios en la Península Ibérica. A pesar de que la investigación arqueológica de las sociedades altomedievales ha conocido un evidente salto cualitativo y un acentuado proceso de internacionalización en los últimos años, el eco de estas aportaciones en nuestro país aún ha sido muy parcial. En buena medida son tres las causas que podrían explicar esta asimetría.

En primer lugar los importantes resultados proporcionados por la arqueología preventiva aún no han sido explotados en toda su potencialidad para llevar a cabo un reexamen de las sociedades altomedievales desde el punto de vista de los registros funerarios. En los últimos años se ha invertido un enorme esfuerzo en sistematizar y "dar sentido" a nuevos registros, como es el caso de los lugares habitados hallados principalmente en los suburbios de ciudades como Madrid o Barcelona (Vigil-Escalera 2007; Roig 2009). La inexistencia de una trayectoria de estudios previos dedicados a esta temática ha favorecido, indudablemente, la construcción crítica de estos registros sin que fuese necesario confrontarse con consistentes paradigmas historiográficos. En cambio, son numerosos los hallazgos de cementerios que han sido simplemente clasificados bajo el epígrafe de 'necrópolis visigodas' ajustándose a los paradigmas dominantes. En realidad hay suficientes elementos como para pensar que los nuevos hallazgos producidos en el interior peninsular o en Cataluña desbordan notablemente estas categorías y cuestionan los paradigmas interpretativos al uso. Los abundantes enterramientos realizados en el interior de los silos (Roig y Coll 2011), la existencia de grupos de tumbas distribuidas en el tejido de los asentamientos rurales y la misma variabilidad y complejidad que muestran las necrópolis comunitarias constituyen un registro 
muy articulado que lleva a cuestionar, entre otros aspectos, las nociones de 'necrópolis' y ‘necrópolis visigodas' (Quirós Castillo y Vigil-Escalera 2011). $\mathrm{Y}$ aunque la mayor parte de las intervenciones aún permanecen inéditas, es indudable que en los próximos años esta temática conocerá un notable desarrollo (p.ej. Vigil-Escalera 2013).

En segundo lugar las aportaciones realizadas por los estudios osteoarqueológicos de los cementerios altomedievales excavados en la Península Ibérica son aún más bien modestas y episódicas. Es cierto que suele ser frecuente la realización de informes técnicos en el marco de proyectos de carácter preventivo o como resultado de la revisión de intervenciones arqueológicas antiguas, aunque normalmente se trata de estudios puntuales que en pocas ocasiones se llegan a editar. Asimismo se han realizado algunos trabajos pioneros sobre los marcadores genéticos de yacimientos como Aldaieta (Alzualde et alii 2006, 2007) o en varios conjuntos madrileños (Fernández Domínguez et alii 2009a; 2009b), pero estamos aún lejos de contar con proyectos de una cierta entidad y de una masa crítica de datos suficiente como para realizar síntesis de cierto calado. Del mismo modo son prácticamente inexistentes los estudios isotópicos de poblaciones altomedievales en nuestro país ${ }^{3}$. En definitiva, queda aún mucho camino por recorrer para poder construir registros funerarios de calidad que permitan integrar los análisis formales con los osteoarqueológicos.

Pero sin ninguna duda, es el campo teórico donde es más acuciante la necesidad de una profunda renovación de los estudios sobre la arqueología funeraria peninsular, ya que estamos convencidos de que una nueva mirada sobre estos registros movilizaría otros recursos y metodologías. Esta inquietud ha sido ya manifestada por varios autores, y en particular por A. Azkarate en un trabajo crítico publicado hace unos años $(2002)^{4}$. No obstante, incluso en publicaciones recientes el paradigma culturalista sigue siendo dominante (Morín y Barroso 2008), de tal forma que las 'necrópolis visigodas' siguen siendo interpretadas como necrópolis de los visigodos en términos normativistas. Y aunque las contradicciones y debilidades que arrastra este paradigma -que por otro lado ha ido modificándose a lo largo del último siglo- han sido subrayadas por varios autores (Collins 2005: 181-194; Quirós y Vigil-Escalera 2011:

\footnotetext{
${ }^{3}$ Entre las excepciones se pueden los trabajos Prevedorou et alii 2010, Fuller et alii 2010; Mundee 2010; Quirós Castillo 2013 o las tesis doctorales actualmente en preparación por parte de S. Inskip, M. I. García y O. López Costas.

${ }^{4}$ Igualmente la reciente traducción al castellano de un trabajo clásico de L. R. Binford (2011) acompañado de una introducción de G. Ripoll es otra prueba tangible de las crecientes preocupaciones por los aspectos teóricos.
}

159-164), las últimas propuestas siguen impregnadas de estos planteamientos (Barroso Cabrera y Moríndo de Pablos 2007: 19; López Quiroga 2010: 264-265). Por otro lado otros especialistas han asimilado las debilidades del paradigma etnicista pero aún no se ha logrado construir un discurso alternativo (Kulikowski 2005: 251; Ripoll 2007: 65; Arce 2011: 40).

Teniendo en cuenta estos antecedentes, sería necesario aprovechar las ocasiones que brinda la arqueología preventiva a la hora de proporcionar nuevos registros para avanzar en estas líneas de trabajo y repensar el significado de los espacios funerarios altomedievales desde la óptica que nos proporciona las nuevas aportaciones producidas en el campo de la arqueología de los espacios rurales.

En este trabajo se presentan los resultados del primer estudio realizado en España de un espacio funerario de los siglos VI-X combinando el análisis de los isótopos ligeros y pesados, lo que permite realizar una serie de inferencias sobre los habitantes del yacimiento de San Martín de Dulantzi (Alegría-Dulantzi, Álava). El empleo de estas técnicas analíticas cuenta ya con una cierta tradición en el estudio de los cementerios altomedievales europeos, y son muchos los autores que consideran que su aportación es y será fundamental para analizar con mayor rigor estos siglos (Härke 2007: 16; Hedges 2011).

Este trabajo se articula en cuatro partes principales. En primer lugar se presenta el registro arqueológico de Dulantzi; en segundo lugar se exponen los métodos analíticos y los resultados obtenidos en el estudio de los marcadores isotópicos; a continuación se analizan las consecuencias de estos registros y se concluye realizando una valoración global.

\section{EL YACIMIENTO DE SAN MARTÍN DE DULANTZI}

Durante los años 2009 y 2010 se ha llevado a cabo una intervención arqueológica preventiva en el barrio de Dulantzi de la villa de Alegría-Dultanzi (Álava) como consecuencia de la reurbanización de la zona (Fig. 1). La villa de Alegría fue fundada por iniciativa de Alfonso XI en el año 1337 sobre la aldea de Dulantzi (Fig. 2), documentada desde el siglo XI y situada en proximidad de la sede de Tullonium, una de las localidades de los Várdulos mencionada por Ptolomeo y nuevamente citada en el itinerario Antonino (Gurruchaga 1951).

La intervención, que ha afectado una extensión de unos $800 \mathrm{~m}^{2}$, ha permitido recuperar una compleja secuencia ocupacional que arranca en la prehistoria y llega 


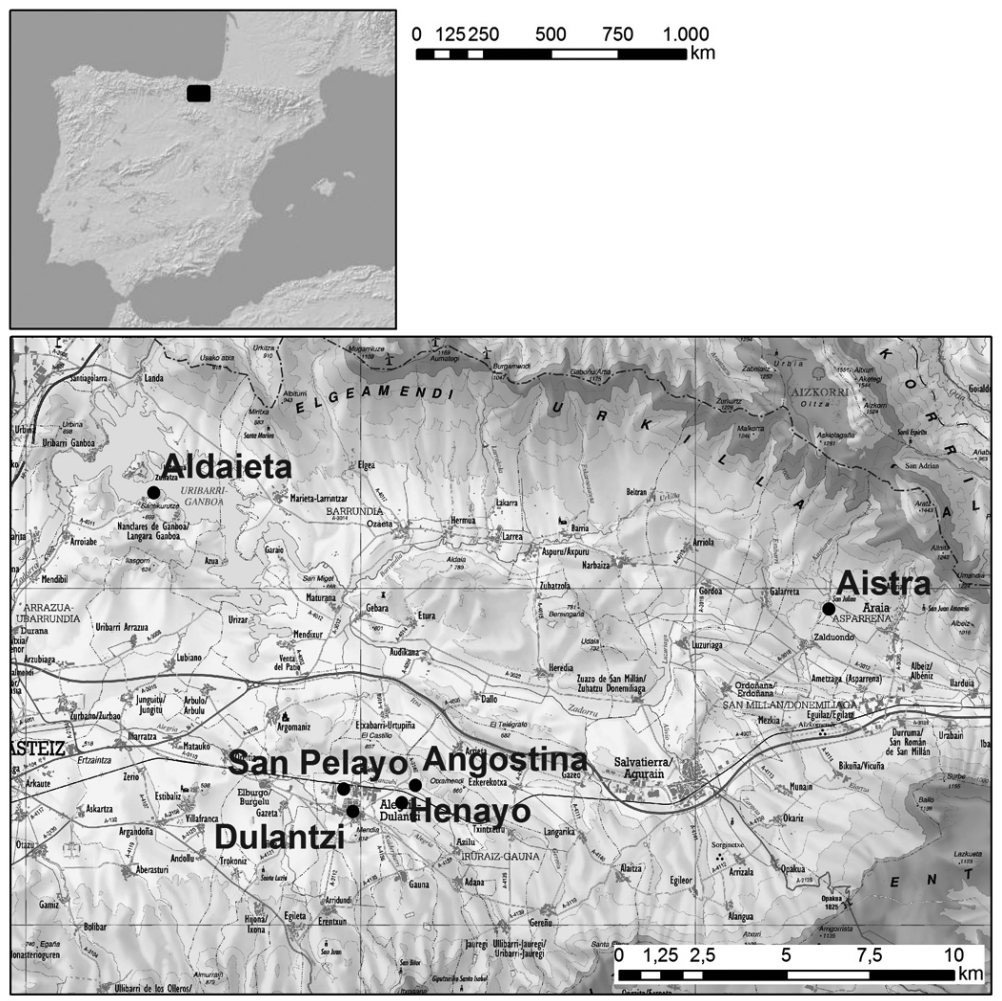

Figura 1. Mapa de localización del yacimiento de Dulantzi (Alegria-Dulantzi, Álava) y de las principales localidades citadas en el texto.

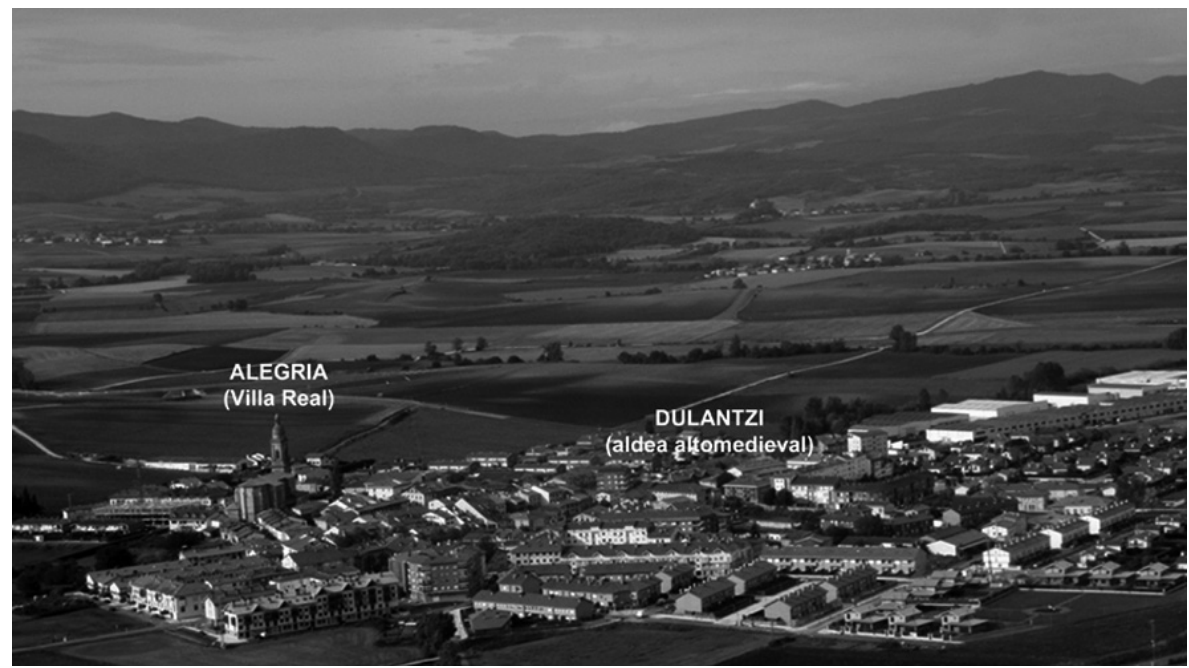

Figura 2. Vista aérea de la villa de Alegría-Dulantzi (Álava).

hasta la actualidad. El carácter urbano del lugar ha condicionado la naturaleza de los depósitos arqueológicos así como la estrategia de la intervención y el carácter fragmentario de los contextos recuperados, de la misma manera que el carácter preventivo de la excavación ha determinado los plazos de ejecución (Fig. 3).
Más concretamente se han reconocido ocho fases de ocupación ${ }^{5}$ (fase 1: ocupación doméstica de la edad del bronce; fase 2: ocupación doméstica al-

\footnotetext{
${ }^{5}$ Una presentación analítica y exhaustiva de la secuencia estratigráfica se puede consultar en Loza y Niso 2012.
} 
1
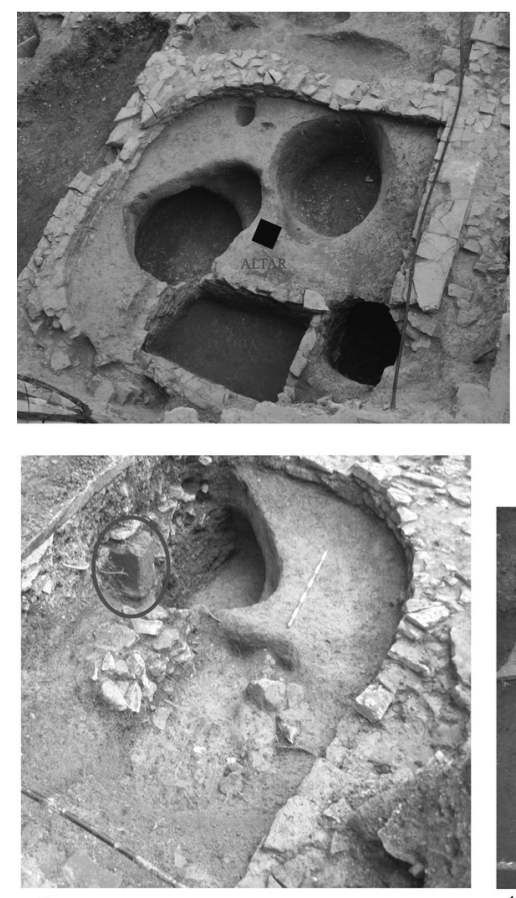

3

4
2
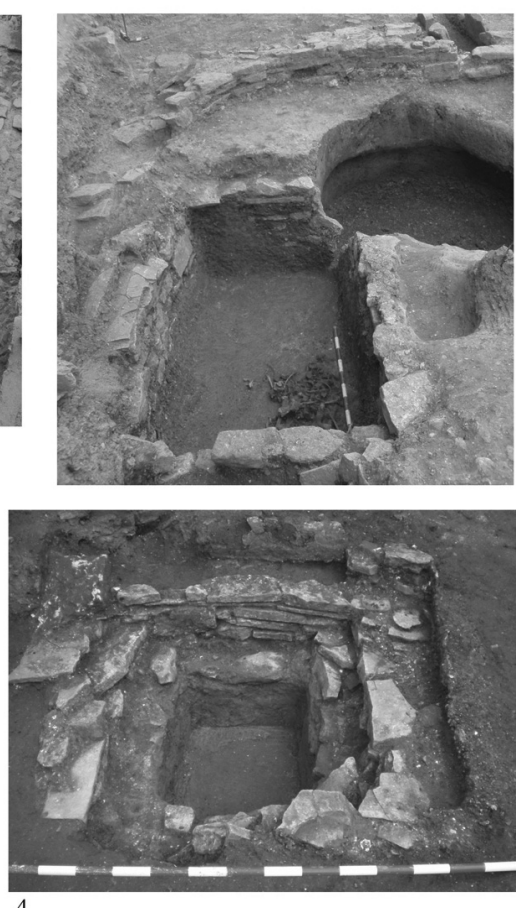

Figura 3. Fotografías generales de la excavación (1. El ábside con la "tumba fundacional"; 2. "tumba fundacional"; 3 . Tenante de altar; 4. Pila identificada como baptisterio).

toimperial seguida por una reestructuración a partir del siglo III carente de estructuras de habitación; fase 3: ocupación de carácter funerario del siglo Vprimera mitad del VI; fase 4: construcción de un edificio religioso y de un cementerio fechables en la segunda mitad del siglo VI y el siglo VII; fase 5: densificación del asentamiento y formación de un amplio cementerio entre finales del siglo VII y el siglo IX; fase 6: transformación de la iglesia y del área funeraria en los siglos X-XII; fase 7: edificación de la nueva iglesia de San Martín, siglos XII-XIV; fase 8: transformaciones recientes, siglos XV-XXI), aunque nuestra atención se centrará en esta ocasión únicamente en las fases 4 y 5 .

Se puede atribuir a la fase 4a la construcción de un edificio de planta basilical conservado únicamente en sus cimientos o con pocas hiladas realizado en un espacio dedicado con anterioridad a un uso funerario y que ha podido ser excavado únicamente de forma parcial (Fig. 4).

El edificio ha sido fechado en un momento indeterminado del siglo VI a partir de la datación radiocarbónica de los restos humanos hallados en una tumba femenina ubicada en el ábside y construida en el momento de la fundación del templo con muros de mampostería y un revestimiento de un enfoscado

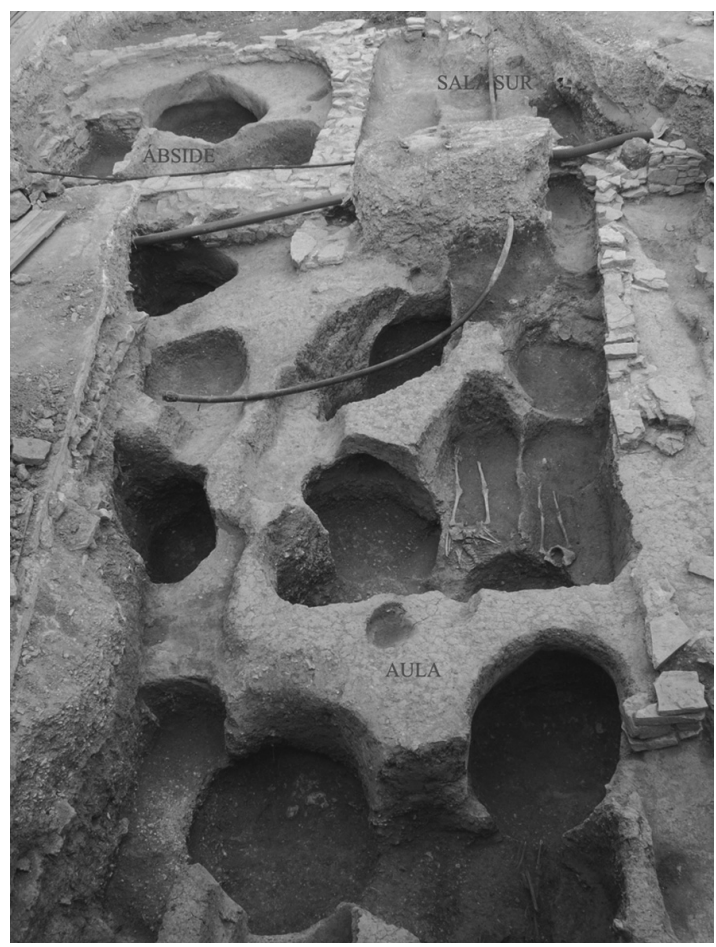

Figura 4. Vista general del aula de la iglesia hallada en Dulantzi (Álava). 


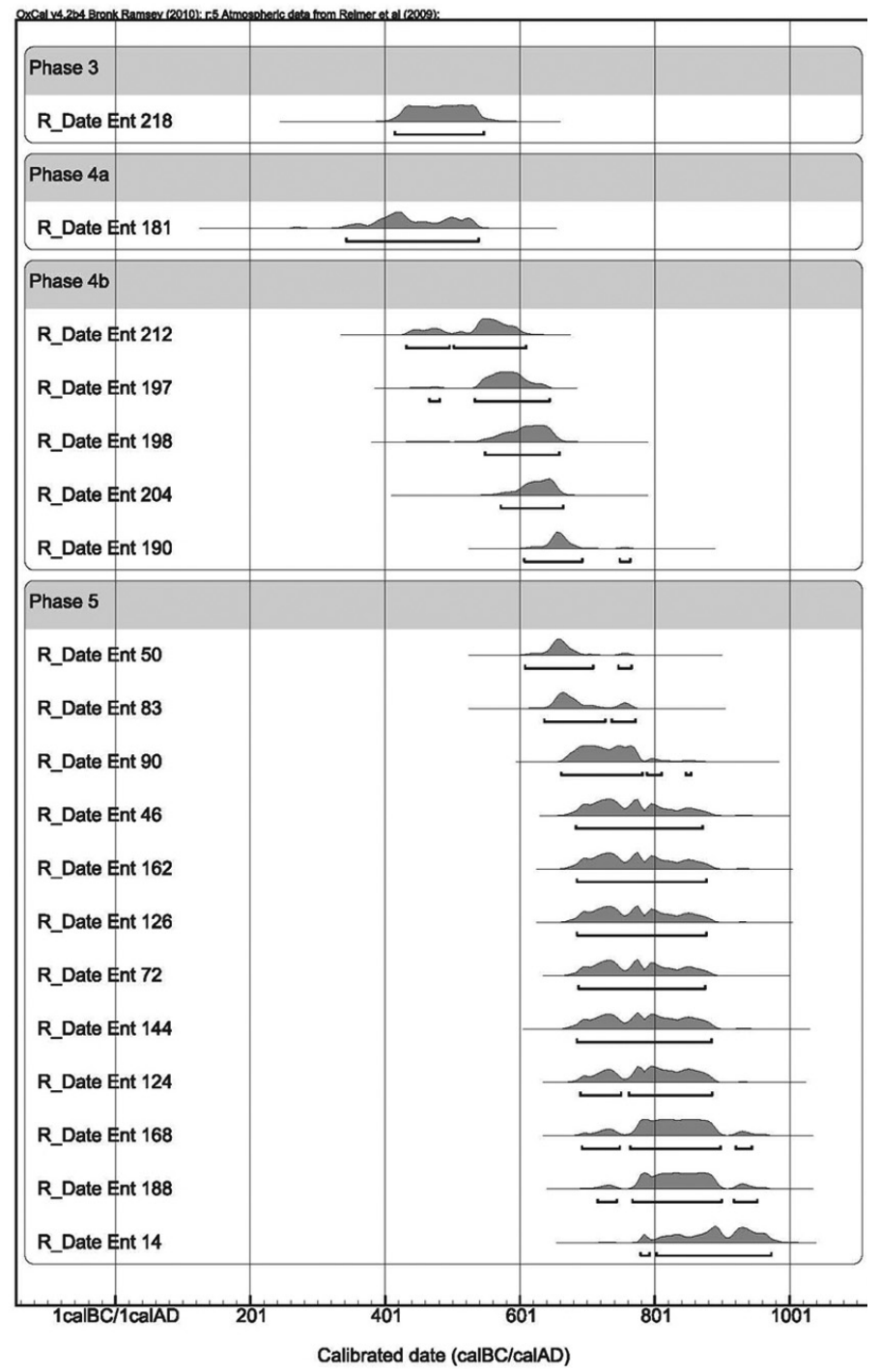

Figura 5. Dataciones radiocarbónicas calibradas de los enterramientos atribuibles a la fase 3 (218), fase 4a (181), fase 4b (197, 212, $204,190)$ y fase $5(46,50,72,83,90,162,188,14,144,168)$.

rosáceo, así como por la datación de otros individuos enterrados en el área con anterioridad ${ }^{6}$ (Fig. 5).

La construcción, realizada con mampuestos y con materiales romanos reutilizados, presenta un ábside semicircular inscrito en un rectángulo con una cámara rectangular contigua ${ }^{7}$, un aula rectangular de al menos 10 x 5 metros presumiblemente dividida en tres naves, y un cuerpo de 4 x 3,5 metros situado al SO dotado de una pila con dos escalones revestida en su

\footnotetext{
${ }^{6}$ La tumba $218(1580 \pm 30 \mathrm{BP})$ es anterior a la construcción del edificio, mientras que los restos humanos de la "tumba fundacional" 181 (1626 \37 BP) están en posición secundaria lo que explica esta aparente contradicción cronológica.

${ }^{7}$ No se ha podido determinar si cuenta con una cabecera tripartita.
}

interior por un enfoscado rosáceo similar al hallado en la tumba fundacional (Fig. 6).

En términos funcionales este edificio ha sido interpretado como una iglesia teniendo en cuenta su morfología y orientación, el hallazgo en el centro del ábside de un fragmento de estela funeraria reutilizada como tenante de altar conservada in situ, la presencia en los niveles de amortización de restos arquitectónicos de celosías, cornisas, tambor de columna, etc., y por último, la identificación de una sala dotada de una pila central como un baptisterio de inmersión (Loza y Niso 2012).

Si se admite esta interpretación, se trataría de un edificio singular en el panorama de la arquitectura 


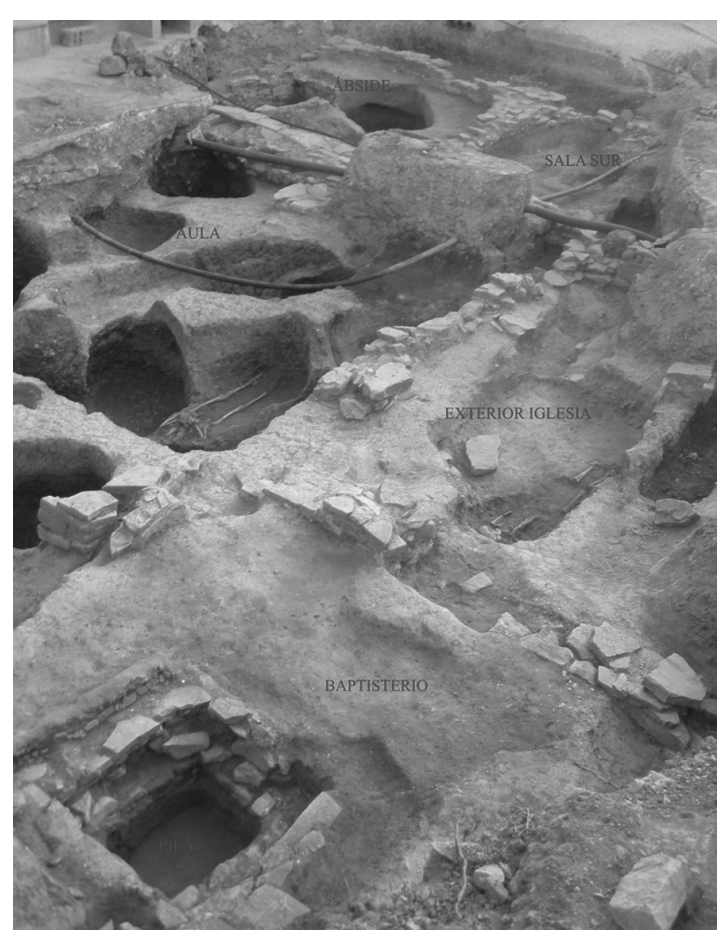

Figura 6. Vista general de la excavación y en primer plano la pila identificada como baptisterio. monumental del norte peninsular, puesto que presenta notables similitudes con otras construcciones realizadas en sectores mediterráneos o en el interior peninsular (Godoy Fernández 1995; Utrero Agudo 2006; Ripoll et alii 2012). En cualquier caso, su cronología es coherente con las dataciones propuestas para la difusión de las iglesias rurales en Hispania (Chavarría Arnau 2006).

En el interior del edificio y en su proximidad se han hallado un número mínimo de diecinueve tumbas (Fig. 7), la mayor parte de las cuáles se localizaba en el aula del templo o en la cámara contigua al ábside, respetándose el ábside y el baptisterio (fase 4b). Todos los individuos han sido enterrados con una orientación E-O, siguiendo la alineación del edificio eclesiástico, y se ha reconocido la existencia tanto de sepulturas múltiples como individuales. Salvo en un caso concreto (215), las tumbas no se reutilizaron, lo que podría indicar una pérdida de la identidad espacial que en cambio se observa en otras 'necrópolis visigodas' coetáneas (Ripoll López 1994) donde la reutilización de las tumbas es bastante común (Contreras 2006).

El hallazgo de numerosos clavos en todas las tumbas de este período testimonia que los enterramientos de esta fase fueron realizados con ataúdes de madera, al igual que en el cercano yacimiento de Aldaieta

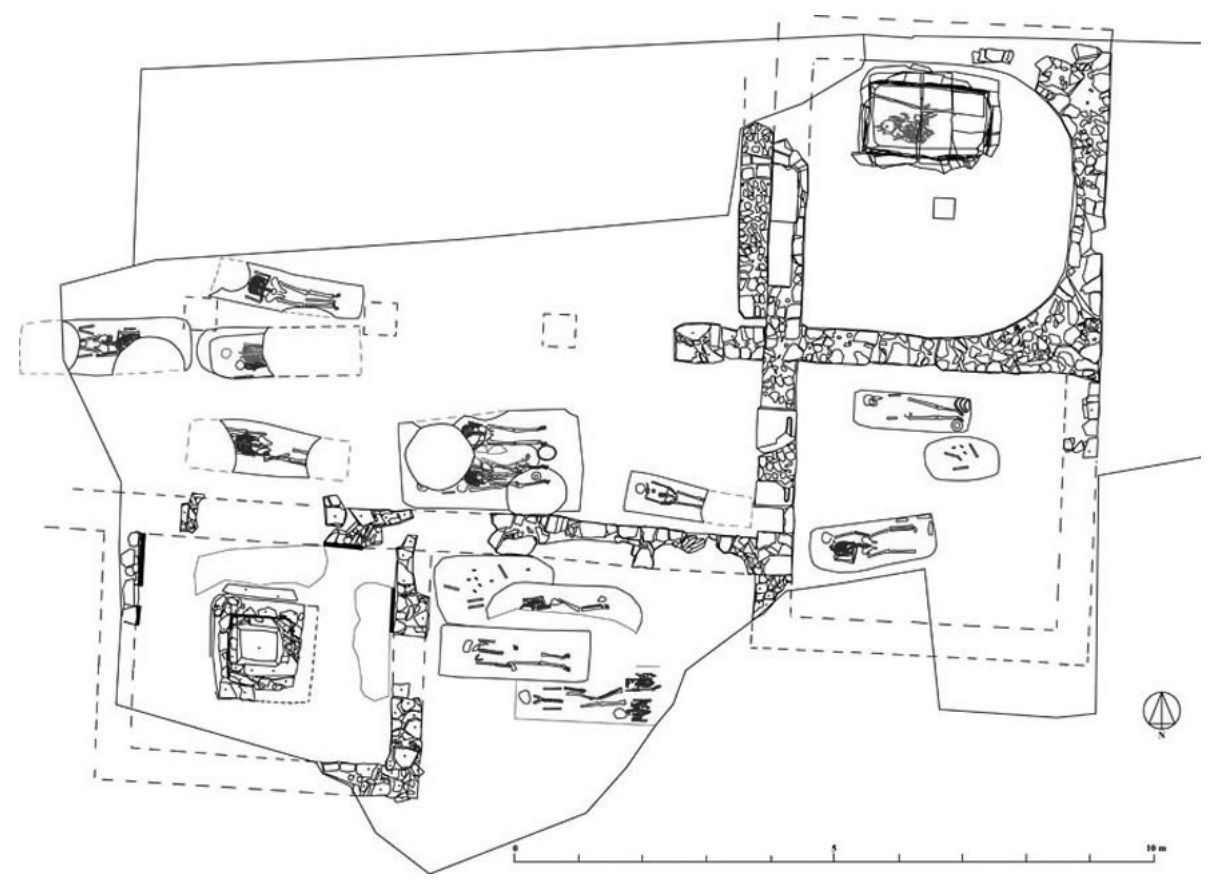

Figura 7. Planta con los enterramientos atribuidos a la fase 4. 
(Azkarate 1999), situado únicamente a unos $10 \mathrm{~km}$ al NO de Dulantzi. Además, en nueve de estas tumbas se han hallado ajuares que comprenden objetos de adorno personal, armas y otros materiales de prestigio (Fig. 8). El número de objetos o de tumbas con este tipo de depósitos pudo ser mayor, puesto que algunos de estos enterramientos se han visto parcialmente destruidos por los silos que fueron abiertos en el interior del templo durante la fase 6 , aunque también tenemos la certeza de que algunos de estos individuos carecían de cualquier tipo de material.

Salvo en un caso (190 con vasija), todos los individuos dotados de este tipo de objetos son hombres adultos, y al igual que en el cercano yacimiento de Aldaieta, la composición de estos ajuares es muy heterogénea, puesto que se combinan las armas, objetos de adorno personal, elementos de prestigio como cuencos de vidrio o de bronce, un cubo y otro tipo de elementos como son dos cucharillas metálicas o piezas cerámicas (Fig.
9). Destacan, en particular, los materiales localizados en una de las tumbas más antiguas halladas en el aula (212) así como otras tumbas atribuibles probablemente al siglo siguiente $(187,215)$. Estos materiales presentan grandes analogías con los hallados en Aldaieta, de tal forma que en el catálogo de materiales de este yacimiento se encuentran paralelos prácticamente para todas las piezas de Dulantzi (Azkarate 1999).

Para datar estos enterramientos se ha asumido la cronología propuesta para el cementerio de Aldaieta segunda mitad del siglo VI hasta inicios del VIII-debido a las analogías existentes entre los materiales de ambos yacimientos, que son compatibles con las dataciones radiocarbónicas realizadas sobre los restos humanos.

Por último hay que señalar que el edificio no estaba aislado. En su exterior se han hallado varios rebajes, estructuras negativas y agujeros de poste fechables entre los siglos VI y VIII que podrían quizás indicar la existencia de algunas estructuras domésticas próximas

\begin{tabular}{|c|c|c|c|c|}
\hline Tumba & Sexo & Edad & Datación & Armas, depósitos y objetos de adorno personal \\
\hline 184 & M & AJ & & Punta de lanza \\
\hline 187 & M & AJ & & Anillo de plata, aplique de cinturón, remates de hierro de cubo de madera y punta de lanza \\
\hline 190 & $\mathrm{~F}$ & $\mathrm{~J}$ & $1365 \pm 32$ & Vasija de cerámica \\
\hline 196 & $\mathrm{~F}$ & A & & \\
\hline 197 & M & AJ & $1490 \pm 30$ & Punta de lanza \\
\hline 198 & M & AJ & $1441 \pm 41$ & \\
\hline 199 & M & AJ & & Cucharilla de bronce, cuenco de bronce \\
\hline 202 & M & AJ & & Francisca, tachuelas de sandalia \\
\hline 203 & M & A & & \\
\hline 204 & M & A & $1417 \pm 35$ & Vasija de cerámica y remates de hierro de cubo de madera y punta de lanza \\
\hline 206 & M & A & & \\
\hline 207 & ind & I & & \\
\hline 208 & M & AJ & & \\
\hline 209 & M & A & & \\
\hline 210 & M & AJ & & \\
\hline 211 & ind & AJ & & \\
\hline 212 & M & A & $1520 \pm 30$ & Cucharilla de plata, anillo de oro, cuenco vidrio \\
\hline 215 & M & A & & $\begin{array}{l}\text { Punta de lanza, hebilla de cinturón con apliques, anillo de plata; anillo de plata, vasija } \\
\text { de cerámica, puñal, hebilla de cinturón y colgante de hueso trabajado }\end{array}$ \\
\hline 216 & F & AJ & & \\
\hline
\end{tabular}

Figura 8. Listado de armas y objetos de adorno personal hallados en las tumbas atribuidas a la fase 4. 

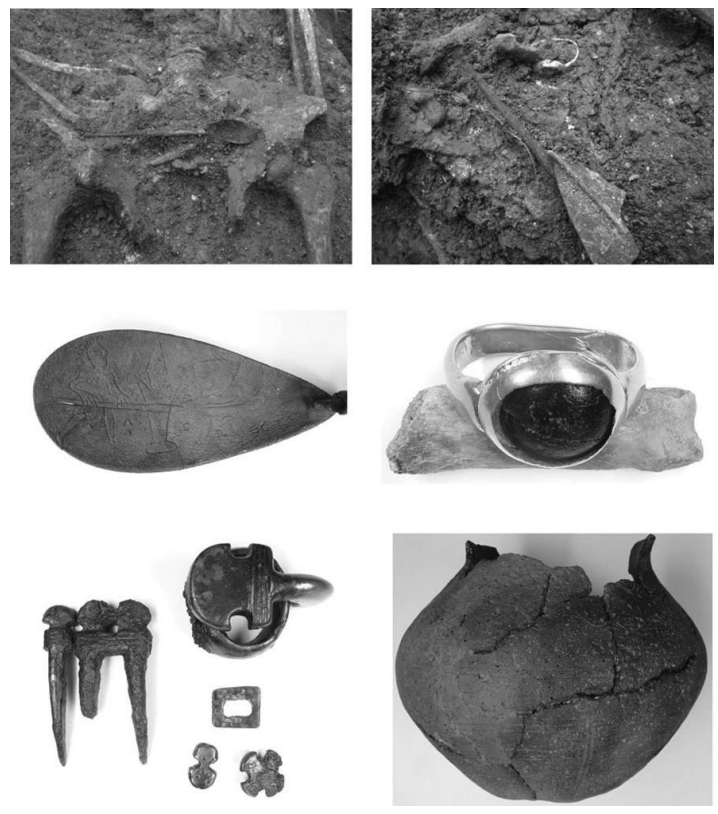

Figura 9. Principales objetos de adorno personal hallados en las tumbas. al templo. Por otro lado se han hallado en el exterior del mismo algunas tumbas que se sitúan cronológicamente en el momento final de la fase 4 o el inicio de la fase 5 (tumbas 50 y 83, coetáneas a la 190), lo que podría indicar que en este momento se estaba empezando a ocupar también el exterior del edificio por varias tumbas.

El arranque de la fase 5 se puede situar entre mediados del siglo VII e inicios del siglo VIII, cuando tuvo lugar una profunda transformación del yacimiento (Fig. 10).

A partir de este momento se produjo una densificación de la ocupación, fenómeno que ha sido documentado en varios yacimientos del País Vasco, como Zaballa, Zornoztegi y quizás Gasteiz, cuyo efecto más significativo en este caso ha sido la ocupación de un amplio espacio con fines funerarios en el exterior de la iglesia. Se han atribuido a esta fase un total de 100

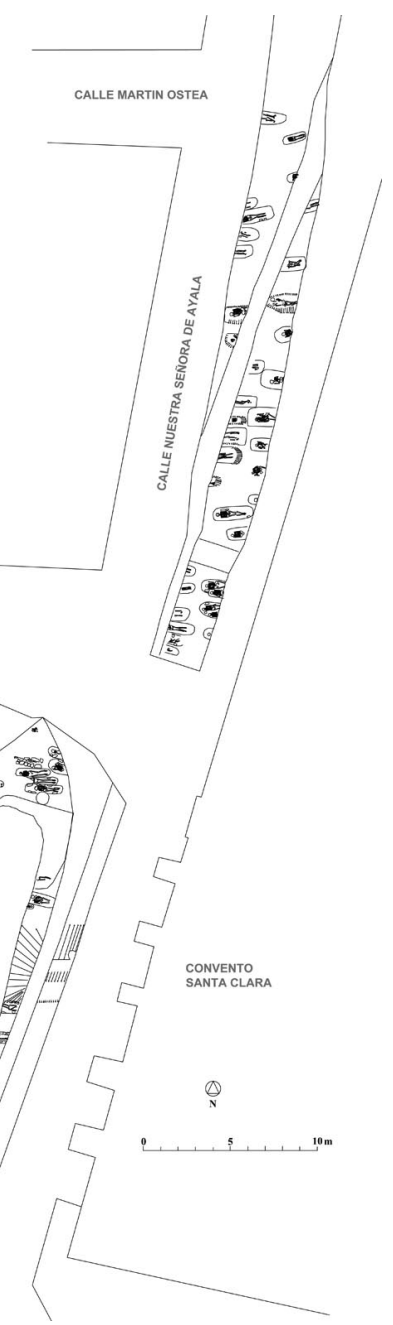

Figura 10. Planta del yacimiento de Dulantzi durante la fase 5. 
tumbas, distribuidas por una amplia extensión que puede ser estimada en unos $1.400 \mathrm{~m}^{2}$. A diferencia de la fase anterior, la iglesia no constituye el eje en torno al cual se articula el espacio funerario, puesto que las tumbas se disponen cubriendo un amplio espacio y su orientación -tendencialmente E-O- tampoco está alineada perfectamente con el eje del templo. Las tumbas no se cortan entre sí, lo que da a entender que la comunidad residente conservaba la memoria física del lugar de deposición de los ascendientes y que, quizás, estaban señaladas. La mayoría de las tumbas han sido excavadas directamente en el sustrato aunque en una veintena de casos han sido delimitadas por muretes y cubiertas por grandes losas. Todas las tumbas de esta fase carecen de ajuares u otro tipo de depósitos, así como de clavos de ataúdes.

Se trata por lo tanto de un cementerio que presenta muchas similitudes con el del cercano yacimiento de Aistra (Zalduondo, Álava), situado a unos $15 \mathrm{~km}$ hacia el NE en línea recta y fechado en los siglos VIII y IX (Mendizabal Gorostizu-Orkaiztegi 2011). También en este lugar se ha hallado un amplio número de tumbas que se distribuyen cubriendo una amplia extensión, sin que se corten entre sí, y las tipologías constructivas son similares a las de Dultanzi (predominio de tumbas excavadas en fosa simple, tumbas de muretes y otras variantes menores).

No se han podido atribuir a esta fase actividades constructivas realizadas en el templo, aunque sí se han hallado en su proximidad restos de construcciones de carácter doméstico que, con posterioridad, han sido amortizadas por la ampliación del cementerio. Se podría sugerir que, al igual que en Aistra en estos siglos, se creó una fuerte división funcional entre el sector funerario y el residencial.

Por último hay que señalar que en la fase 6 , fechable entre los siglos X y XII, se abrieron en el interior de la iglesia un amplio número de grandes silos que cortaron los depósitos anteriores, seccionando algunas de las tumbas atribuidas al período 4b. La disposición de estos silos permite inferir que el edificio seguía aún en alzado, aunque resulta mucho más complejo determinar si seguía teniendo o no un uso cultual.

En síntesis, en un momento indeterminado del siglo VI se fundó una construcción de carácter monumental que ha sido interpretada como iglesia, amortizando un espacio anteriormente empleado con fines funerarios y domésticos, quizás en la periferia de una ocupación tardorromana. La iglesia, que no estaba aislada puesto que en su proximidad se han hallado algunos espacios domésticos, formaba parte de un establecimiento difícil de caracterizar debido a la limitada extensión de la intervención realizada. Sin embargo, su proximidad a los hallazgos de San Pelayo (colina situada a unos $700 \mathrm{~m}$ al NO de Dulantzi en la que se han hallado conjuntos funerarios de este mismo período, Iriarte Kortázar 1998; Azkarate 2005), podría llevar a pensar que o bien Dulantzi y San Pelayo formaban parte de un único gran yacimiento, o bien que eran establecimientos de dimensiones reducidas entre sí.

Lo que sí parece claro es que la iglesia de Dulantzi se convirtió entre finales del VI y todo el siglo VII en un lugar donde se enterró un colectivo diferenciado internamente, tal y como muestra el uso o la ausencia de ajuares y depósitos de variada naturaleza en el interior de las tumbas. Podría tratarse, por lo tanto, de una iglesia privada relacionada con la presencia de élites locales, tal y como se observa en otros territorios próximos (Chavarría Arnau 2009: 167-169).

Hacia inicios del siglo VIII se formó en torno a la iglesia un asentamiento probablemente más denso y de mayores dimensiones. Y aunque no se han hallado más que un número reducido de estructuras de habitación, la densidad de las tumbas halladas en relación con el espacio excavado es un indicio que permite inferir que el yacimiento tenía entonces una mayor entidad. Quizás lo más sorprendente es que la iglesia (¿también sus propietarios?) ha perdido la centralidad que tenía en la fase anterior.

\section{MÉTODOS Y MATERIALES}

El estudio de los marcadores isotópicos se emplean en arqueología desde hace decenios, sustancialmente con el fin de determinar el paleoclima, la dieta o la movilidad de las poblaciones antiguas (DeNiro 1987; Pollard y Heron 2008; Malainey 2010). En el caso del yacimiento de Dulantzi se han analizado los isótopos de nitrógeno y de carbono de 65 individuos para estudiar su dieta, y en 32 esqueletos los de estroncio para determinar si su origen era local o si, en cambio, se trataba de inmigrados ${ }^{8}$. Se presentarán a continuación los resultados de estos estudios de forma separada, haciendo una breve referencia a los principios analíticos.

\subsection{La paleodieta de los habitantes de Dulantzi}

El principio sobre el que se basa el análisis de la paleodieta es que los isótopos de carbono y nitrógeno

\footnotetext{
${ }^{8}$ El estudio osteoarqueológico del yacimiento ha sido realizado por T. Fernández Crespo (Fernández Crespo 2011), y será publicado de forma detallada en la monografía de la intervención que actualmente está en preparación.
} 
son asimilados por los humanos mediante la alimentación, de tal forma que la medida de las relaciones isotópicas de los restos antropológicos recuperados en las excavaciones proporciona informaciones sobre su dieta (Schwarcz 1991; Ambrose 1993; Sealy 2001). A través del estudio del colágeno presente en los huesos es posible determinar las principales fuentes proteínicas consumidas y determinar los patrones alimentarios a largo plazo.

Las medidas de los isotopos de carbono (expresadas en términos de $\delta^{13} \mathrm{C} \%$ puesto que hacen referencia a un estándar) permiten determinar si las proteínas consumidas son de origen marino o terrestre, o si prevalece el consumo de plantas $\mathrm{C}^{3}$ (mayoritarias en Europa y que incluyen cereales como el trigo o la cebada) frente a las $\mathrm{C}^{4}$ (de origen tropical y adaptadas a climas templados, que incluyen cereales de ciclo corto) (Schoeninger y De Niro 1984; Heaton 1999).

Asimismo, las medidas de los isótopos de nitrógeno (expresadas igualmente en relación a un estándar, $\delta^{15} \mathrm{~N}$ $\%$ o) permiten determinar la proporción de proteínas vegetales consumidas respecto a las de origen animal, o reconocer el consumo de alimentos fluviales o marinos, constituyendo un indicador de la posición en la cadena trófica discriminando entre la dieta herbívora, carnívora u omnívora (Hedges y Reynard 2007).

Por lo tanto, a través de estas medidas es posible determinar el nivel trófico en el que se encuentran los individuos analizados e identificar los ecosistemas marinos y terrestres, y dentro de ellos, los herbívoros respecto a los omnívoros o los carnívoros (Schoeninger y De Niro 1984). Por otro lado, aunque las medidas isotópicas permiten reconocer las principales fuentes proteínicas, no permiten identificar alimentos concretos, el consumo de los diferentes productos animales (p. ej. diferenciar la leche del queso o de la carne de un herbívoro) ni la dieta en su conjunto (Richards y Hedges 1999).

Teniendo en cuenta estos principios, se han analizado un total de 65 restos humanos, además de 11 huesos de fauna9. Más concretamente se han analizado 16 individuos de la fase 4 ( 1 de la fase 4 a y 15 de la fase $4 \mathrm{~b} ; 8$ con ajuares y 8 carente de ellos); 42 individuos de la fase 5 y 7 de la fase 6 . Los valores medios obtenidos permiten inferir que la dieta de la población altomedieval de Dulantzi se basa en el consumo de recursos $\mathrm{C}^{3}$, con una aportación en casos puntuales de $\mathrm{C}^{4}(-19,8 \pm 1,4$ $\delta^{13} \mathrm{C} \%$; $9,2 \pm 1,2 \delta^{15} \mathrm{~N} \%$ ). Estos valores, en particular los de nitrógeno, son ligeramente inferiores a los obtenidos en otros cementerios coetáneos anglosajones,

\footnotetext{
${ }^{9}$ Análisis realizados en la Seconda Università di Napoli, Dipartimento di Scienze Ambientali, Laboratorio CIRCE-IRMS. Los criterios de muestreo, las técnicas y los protocolos analíticos seguidos y la interpretación detallada de los resultados obtenidos en este y en otros yacimientos próximos se puede consultar en Lubritto et alii 2012 y Quirós Castillo 2013.
}

donde se ha constatado un consumo de caza y recursos salvajes más abundante del que se observa en los registros arqueofaunísticos altomedievales del País Vasco (Mays y Beavan 2012: 870). En cambio, los valores medios de Dulantzi (siglos V-XI) son sustancialmente más elevados respecto a los de Aistra (siglos VIII-IX), único contexto altomedieval próximo analizado hasta el momento $\left(7,9 \pm 1,0 \delta^{15} \mathrm{~N} \%\right.$ ) en nuestro territorio (Quirós Castillo et alii 2012).

Los análisis estadísticos de las medidas de Dulantzi han permitido realizar dos inferencias de gran interés. En primer lugar, se ha observado que existe una correlación entre las variaciones de los valores de $\delta^{15} \mathrm{~N}$ y la distribución cronológica (Mann-Whitney $\mathrm{p}=0,010$ ). Dicho de otra forma, los valores obtenidos en el cementerio de la fase 4 , pertenecientes a individuos que hemos interpretado como grupos de poder local, son más elevados respecto a los de la fase 5 y son similares a los de la fase 6 (Fig. 11). Estas variaciones, que no se pueden vincular directamente con un cambio en la fuentes de abastecimiento proteínico (Fig. 12), permiten sugerir que el consumo de proteínas animales fue más elevado en los siglos VI-VII y X-XI que en el VIII-IX.

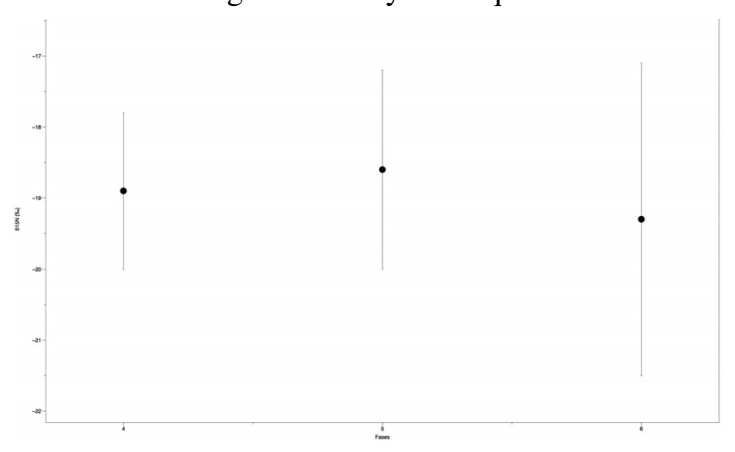

Figura 11. Valores medios y desviación estándar de las medidas de $\delta^{13} \mathrm{C} \%$ de los individuos analizados de Dulantzi de las fases 4,5 y 6 .

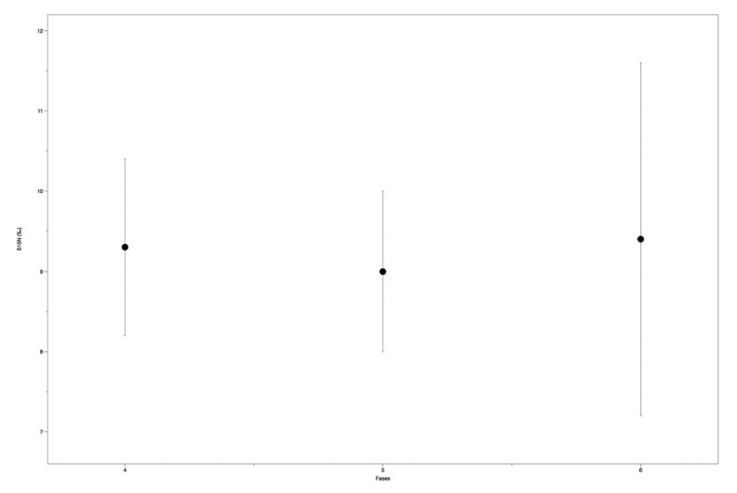

Figura 12. Valores medios y desviación estándar de las medidas de $\delta^{15} \mathrm{~N} \%$ de los individuos analizados de Dulantzi de las fases 4,5 y 6. 
En segundo lugar, el análisis interno de los individuos atribuidos a la fase 4 ha mostrado que no hay una diferencia entre los patrones alimentarios de los individuos enterrados en el interior de la iglesia con ajuares y aquéllos que carecen de ellos $\left(\delta^{15} \mathrm{~N}\right.$ Mann-Whitney $\mathrm{p}=0,195, \mathrm{n} \mathrm{15}$ ). Por lo tanto se puede inferir que el empleo de estos objetos en contextos funerarios no implica la existencia patrones alimentarios diferenciados.

\subsection{Movilidad de los habitantes de Dulantzi}

Desde hace unos años varios grupos de investigadores han comenzado a realizar estudios de forma sistemática de los isótopos con el fin de identificar en los cementerios altomedievales la presencia de inmigrantes y verificar la validez de los planteamientos migracionistas, negacionistas o culturalistas a los que nos hemos referido con anterioridad (Brettell et alii 2012). Aunque son varias las estrategias analíticas empleadas (Malainey 2010) como es el caso del estudio de los isótopos de oxígeno, en este proyecto se ha recurrido a los de estroncio.

Los valores de la relación isotópica de ${ }^{87} \mathrm{Sr} /{ }^{86} \mathrm{Sr}$ en cada región varían en función de la edad y la composición química del sustrato rocoso, de tal forma que estas relaciones isotópicas quedarán registradas en los animales y los humanos que viven en un determinado lugar, puesto que se fijan en los organismos a partir del consumo de alimentos y de agua. De esta manera, las personas que han consumido alimentos de un determinado lugar connotado por una determinada composición isotópica tendrán relaciones isotópicas en huesos y dientes propios del lugar donde han vivido. En cambio, las relaciones isotópicas del esmalte dental que se ha formado en la infancia, hacen referencia únicamente al lugar de nacimiento. Por lo tanto, el contraste entre ambas medidas permite inferir el desplazamiento de personas (Bentley 2006). Además, en aquellos lugares en los que se han realizado proyectos más amplios, midiendo las características del sustrato rocoso, es posible inferir el lugar de proveniencia de los inmigrados (Müldner et alii 2009; p.ej. Chemery et alii 2010).

La ausencia de una masa crítica de estudios sobre el estroncio en nuestro territorio ${ }^{10}$ impide, por el momento, determinar el área compatible con las medidas isotópicas de los migrados, y por lo tanto, proponer un área de proveniencia. Por otro lado, hay que tener en cuenta que esta técnica analítica permite identificar la primera generación de migrados que conservan tanto los marcadores isotópicos del área de origen como el de destino; en cambio no permite reconocer a los descendientes crecidos in loco.

En el caso de Dulantzi se han hecho cincuenta medidas de 6 muestras de sedimento y 32 muestras de individuos pertenecientes a varias fases: 1 de la fase 3, 20 de la fase 4 ( 1 de la 4 a y 19 de la 4 b, de los cuales 9 con ajuares y 10 sin ellos), 9 de la fase 5 y 1 de la fase $6^{11}$. Los resultados de los análisis han mostrado la existencia de tres rangos de valores isotópicos que permiten diferenciar los individuos de origen local y dos grupos de inmigrantes (Fig. 13). La mayor parte de los individuos

\footnotetext{
${ }^{10}$ El único trabajo que conocemos relativo al período altomedieval es el estudio sobre la maqbara de la Plaza del Castillo en Pamplona a partir de los isótopos de $\mathrm{Sr}$ y $\mathrm{O}$ que ha confirmado el origen norteafricano de los inhumados (Prevedorou et alii 2010).

11 Análisis realizados en la Universidad del País Vasco/ Euskal Herriko Unibertsitatea. Los criterios de muestreo, las técnicas y los protocolos analíticos seguidos y la interpretación detallada de los resultados obtenidos se puede consultar en Ortega et alii 2012 y Ortega et alii 2013.
}

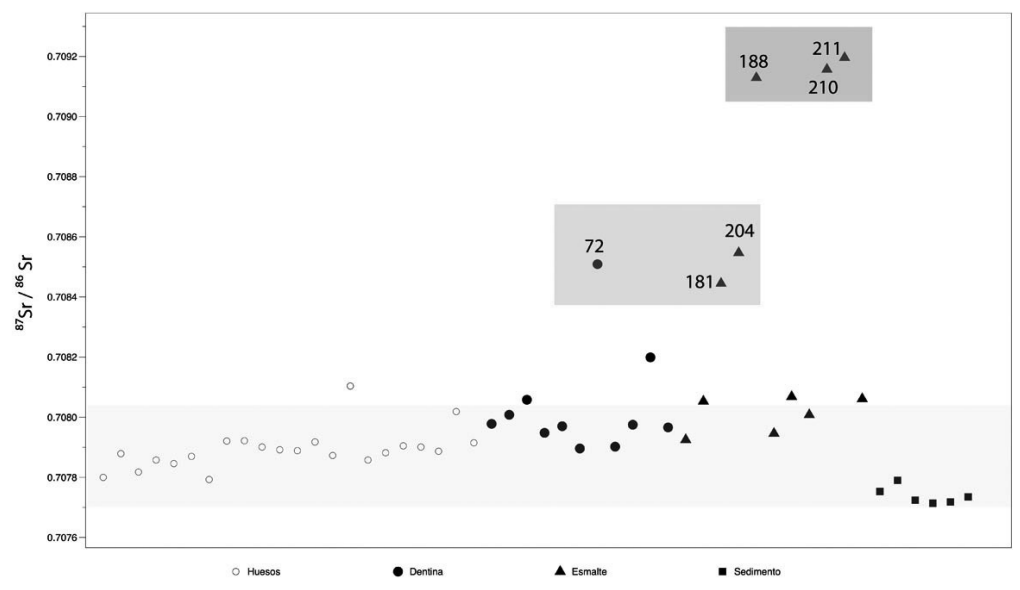

Figura 13. Variación isotópica de las medidas de huesos, costillas, dentina, esmalte y sedimentos en el que se han identificado los dos grupos de inmigrados (Ortega et alii 2013). 
analizados son autóctonos, puesto que presentan valores comprendidos dentro del rango de las aguas locales. En cambio hay otros dos grupos que pueden ser considerados como alóctonos y en los que se incluyen seis individuos: tres de ellos han sido atribuidos a la fase $4 \mathrm{~b}(204,210$ y 211), otro a la fase 4a (la 'tumba fundacional' 181) y dos a la fase 5 (72 y 188). A partir de estas medidas se pueden realizar toda una serie de inferencias.

En primer lugar, no hay correspondencia entre el ritual funerario (uso / ausencia de ajuares) y la procedencia de los individuos. De hecho, solamente uno de los emigrantes (204) cuenta con ajuares, mientras que los otros dos alóctonos de la misma fase (fase 4b) carecen de ellos (fig. 8).

En segundo lugar, la distribución de estos valores a lo largo del tiempo y su incidencia estadística permite pensar que la movilidad de personas de distinto sexo en la alta edad media no era infrecuente, aunque no ha sido un fenómeno cuantitativamente significativo ni es un rasgo específico de los siglos VI y VII: de los 19 individuos atribuidos a la fase $4 \mathrm{~b}$, solamente $3(16 \%)$ son alóctonos.

En tercer lugar resulta aún difícil determinar la procedencia de estos dos grupos de alóctonos, aunque las medidas isotópicas son compatibles entre otros con los valores obtenidos en el agua de varios cursos fluviales de la Galia (Ortega et alii 2013).

En cuarto y último lugar resulta muy interesante constatar que la mujer hallada en la 'tumba fundacional' de la fase 4a (tumba 181) no es de origen local, lo que abre toda una serie de posibilidades a la hora de interpretar cómo tuvo lugar el proceso de fundación de la iglesia hallada en Dulantzi.

\section{DISCUSIÓN DE LOS RESULTADOS}

La interpretación de los resultados obtenidos en el yacimiento de San Martín de Dulantzi se ve dificultada por el hecho de que aún no contamos con otros trabajos que hayan estudiado los mismos registros en otros lugares próximos con los que establecer una comparación, aunque son varios los contextos europeos con los que existen algunas analogías.

Los análisis realizados sobre los isótopos de estroncio han permitido concluir que la muestra analizada de Dulantzi es una sociedad local, de tal forma que el uso de ajuares y depósitos que presentan analogías con otros contextos funerarios al norte de los Pirineos (Azkarate 1999) no son marcadores que permitan identificar a inmigrantes.

Se trata de una conclusión que no resulta sorprendente si se toman en consideración otros estudios si- milares realizados en varios contextos europeos que muestran que no existe una correlación directa entre el uso de ajuares atribuibles a 'culturas' u 'horizontes' arqueológicos lejanos y el reconocimiento de inmigrantes o la identificación étnica de un determinado grupo. Revisten un particular interés aquellos trabajos que han podido confrontar las pautas de movilidad a través de los marcadores isotópicos de oxígeno y estroncio con las atribuciones culturalistas realizadas a partir de los ajuares y los objetos hallados en las tumbas. Son muy numerosos los casos en los que, reconociendo con certeza la existencia de inmigrantes a partir de los marcadores isotópicos, hay una clara contradicción entre los orígenes propuestos por los estudiosos de los objetos y los marcadores isotópicos. Entre los varios ejemplos se puede mencionar el estudio sobre los cuarenta individuos procedentes del cementerio tardorromano de Lankhills School en Winchester, donde se pudo identificar la existencia de individuos procedentes del área húngara y del Mediterráneo, aunque no hay una correspondencia entre su origen y la proveniencia de los objetos, de tal forma que los autores de este estudio han concluido que "in many cases burial practice was dictated by factors other than 'ethnicity' or place of origin, such as kinship, marriage or cultural and political preferences" (Eckardt et alii 2009: 2824). Igualmente en el estudio de los cementerios bávaros de Altenerding y StrubungBajuwarenstrasse se pudo constatar que los marcadores isotópicos permitían identificar con claridad un amplio número de inmigrantes, especialmente mujeres. No obstante, las mujeres que presentaban cráneos modificados siguiendo un ritual tradicionalmente atribuido a los alóctonos eran de origen local y no se detectó una correlación estadística significativa entre la presencia, cantidad y riqueza de los ajuares y el origen de los inmigrantes (Hakenbeck et alii 2010: 241-245). Asimismo en el yacimiento anglosajón de West Heslerton se ha podido constatar que había enterramientos con armas tanto en individuos locales como inmigrantes y que no había una correlación entre el empleo de los objetos funerarios y los patrones de movilidad detectados (Montgomery et alii 2006: 133-134).

Aunque el estudio isotópico realizado sobre el cementerio de Dulantzi es aún un caso aislado, sus resultados se pueden confrontar con otros marcadores. En el ya mencionado yacimiento de Aldaieta (Azkarate 1999), fechado entre mediados del siglo VI y e inicios del siglo VIII, se ha llevado a cabo uno de los primeros análisis paleogenéticos sistemáticos sobre poblaciones altomedievales de toda la Península. Los estudios realizados sobre el ADN mitocondrial y los cromosomas $\mathrm{Y}$ de un total de 65 de los 105 individuos 
recuperados han permitido identificar la existencia de grupos familiares de un asentamiento estable formado sustancialmente por individuos locales, sin que se haya podido determinar con total seguridad la existencia de inmigrantes (Alzualde et alii 2006: 401). Se ha podido inferir, además, que se trata de una comunidad internamente jerarquizada o estratificada en la que el estatus social se transmitiría entre los miembros de la misma familia (Alzualde et alii 2007: 162). Tampoco en este caso los resultados obtenidos en Aldaieta son excepcionales. De hecho, son varios los estudios realizados sobre el ADN mitocondrial en cementerios altomedievales europeos dotados de ajuares que no han proporcionado evidencias de inmigrantes (p.e. Berinsfield et alii 2002: 780; Härke 2011: 4).

En definitiva, aunque hay que ser aún muy cautos, puesto que todavía contamos con una masa crítica de análisis más bien reducida, todos los estudios disponibles permiten concluir de forma provisional que la lectura normativa y etnicista no puede ser aplicada en el caso de Dulantzi. Siempre se podría argumentar que únicamente se han estudiado descendientes de migrantes que han crecido in loco, pero los estudios genéticos realizados en Aldaieta van en contra de esta interpretación. En cualquier caso, es muy significativo señalar que, durante más de un siglo tras la supuesta migración, una parte de estos individuos continuaba construyendo su identidad a través del empleo de armas, objetos de adorno personal y otros materiales para los que se podría sugerir una proveniencia al norte de los Pirineos. En definitiva, parece que el empleo de estos materiales forma parte de una estrategia de visibilidad de la jerarquía interna de una comunidad local que se entierra en el interior o en proximidad de uno de los pocos edificios de culto conocidos hasta el momento en esta zona, formando parte de una verdadera estrategia de distinción, por utilizar la feliz expresión de Walter Pöhl (Pöhl 1998a).

La interpretación de los patrones alimentarios reconocidos a través de los isótopos ligeros de nitrógeno y carbono plantea igualmente escenarios interpretativos de gran interés. Los resultados analíticos muestran que no hay una diferencia de los patrones alimentarios de los individuos dotados o carentes de ajuares y otros materiales de carácter funerario. Esta observación contrasta con otros estudios realizados en varias necrópolis altomedievales europeas, como las de Weingarten (Schutkowski et alii 1999), donde se ha observado una correlación entre la riqueza de los ajuares y los valores de $\delta^{15} \mathrm{~N}$. Asimismo, en el cementerio tardorromano británico de Poundbury Camp hay una correlación directa entre los patrones alimentarios y el enterramiento en mausoleos, ataúdes de plomo y ataúdes de madera (Richards et alii 1998).
Esta constatación nos permite sugerir que la pequeña comunidad enterrada en la iglesia de Dulantzi durante los siglos VI y VII era más homogénea de lo que la composición o incluso la ausencia de ajuares deja entrever, o bien que la jerarquización social no se veía reflejada en el acceso a los distintos recursos alimenticios. Aún no contamos con otras medidas isotópicas relativas a enterramientos de estos siglos con los que confrontarnos en el País Vasco y su entorno, pero resulta significativo constatar que en términos diacrónicos sus valores medios de $\delta^{15} \mathrm{~N}$ son mucho más elevados que los hallados en otros cementerios vascos de los siglos VIII-XI (Quirós Castillo 2013). Todos estos argumentos sugerir que estos individuos, o al menos una parte de ellos, formaron parte de una élite local, probablemente fundadora y propietaria de una iglesia privada, que utilizó este templo como lugar privilegiado de enterramiento. Resulta muy difícil valorar, con los registros disponibles, cuál era la escala a la que operaban estas élites, y de hecho, este es uno de los principales problemas que habrá que abordar en el futuro.

Esta preeminencia social, en cambio, se diluye a partir del siglo VIII cuando se densifica la ocupación y desaparecen algunos de los marcadores arqueológicos del período anterior (ausencia de ajuares; valores de ${ }^{15} \mathrm{~N}$ más bajo; pérdida de la centralidad de la iglesia en la ordenación del espacio funerario; recurso a un nuevo ritual funerario que mantiene la memoria espacial de los inhumados) siguiendo un fenómeno ampliamente contrastado en el País Vasco (Quirós Castillo 2011a).

En definitiva, ¿qué significado tiene el uso de objetos hallados en las tumbas de Dulantzi? Cada vez resulta más evidente que el historicismo cultural, que tanta influencia ha tenido y sigue teniendo en España, resulta absolutamente inadecuado para explicar muchos yacimientos altomedievales de los siglos VI y VII en la Península (Quirós Castillo y Vigil-Escalera 2011; Quirós Castillo 2011b), e indudablemente el caso de Dulantzi constituye, por si fuese necesario, otra prueba más. Pero por otro lado, el negacionismo de los procesos migratorios que ha sido denunciado por numerosos autores (Valenti 2009) tampoco parece ser una estrategia muy operativa para explicar estas sociedades.

De momento en Dulantzi, y en general en el País Vasco, no contamos con evidencias de inmigrantes en contextos de los siglos VI y VII (salvo la 'tumba fundacional' 181 y las tumbas 204, 210 y 211), pero es evidente que toda una serie de objetos de este período, presuntamente importados desde el continente mediante sistemas de intercambio -comercial o no- o realizados a escala local, eran significativos a esca- 
la local y favorecían la construcción de identidades situacionales (Härke 2007). Pero reconociendo los significantes, no resulta demasiado fácil establecer los significados en términos absolutos y muchas de las propuestas interpretativas realizadas sobre estos cementerios como lugares de confrontación social, coherentes con el contexto histórico, se enfrentan al problema de su difícil validación cayendo en el peligroso campo de la especulación. S. Hakenbeck ha mostrado en Baviera la existencia de una compleja red de identidades de tal forma que "objects can have many meanings: these meanings can change or be of different relevance in difference social situations" (Hakenbeck 2007: 25). En nuestra opinión el uso de estos ajuares en los enterramientos de Dulantzi tiene un carácter de marcador social, pero queda por aclarar por qué algunos individuos carecen de ellos, o por qué otros tienen un mayor número de ellos en una comunidad que mantiene niveles de vida, por usar la expresión de C. Dyer (1991), relativamente homogéneos. Quizás identifican líderes locales o grupos familiares que han adquirido una relevancia social en Dulantzi, pero no tenemos marcadores que permitan definir grupos aristocráticos.

\section{CONCLUSIÓN}

Los datos de los que disponemos hasta la actualidad sobre la movilidad de las poblaciones de los siglos VI y VII en el País Vasco muestran la preeminencia de comunidades locales en las cuáles el uso de objetos de adorno personal, armas y otros materiales han de leerse sustancialmente en términos de marcadores sociales y no de indicadores de carácter étnico en el seno de comunidades internamente jerarquizadas. Por otro lado, los patrones alimentarios que se pueden inferir a partir de los estudios isotópicos de los individuos de Dulantzi proporcionan los valores proteínicos más elevados de las poblaciones altomedievales estudiadas hasta el momento en España.

No obstante, conviene ser especialmente cautos a la hora de generalizar estas conclusiones. Los datos de los que disponemos son aún demasiado escasos y los estudios que se están realizando en los últimos años en varios países europeos muestran una realidad extremadamente compleja que no hacen sino mostrar las enormes limitaciones de los marcos conceptuales que manejamos (Hedges 2011; Brethell et alii 2012). Los avances que se están produciendo en los últimos años como resultado de la generalización de los estudios genéticos e isotópicos están renovando y van a renovar profun- damente nuestro conocimiento sobre este período. La reducción de los costes analíticos y la creciente toma de conciencia por parte de los arqueólogos de las informaciones que se pueden obtener a través de estos estudios permiten augurar su generalización en un futuro próximo. Pero para rentabilizar históricamente estos nuevos registros será preciso desarrollar nuevos modelos arqueológicos interdisciplinares (Härke 2011) y repensar críticamente la noción de etnicidad (Jones 1997; Fernández Götz y Ruiz Zapatero 2011), especialmente en un contexto creativo y fluido como el actual, marcado por la superación de muchos de los paradigmas posprocesuales que habían sido innovadores e influyentes durante los últimos dos decenios (Johnson 2010: 220-223).

\section{BIBLIOGRAFÍA}

Alzualde, A., Izagirre, N., Alonso, S., Alonso A., Albarrán, C., Azkarate, A. y de la Rúa, C. 2006: "Insights into the 'isolation' of the Basques: mtDNA lineages from the historical site of Aldaieta (6th7th centuries AD)", American Journal of Physical Anthropology 130, 394-404.

Alzualde, A., Izagirre, N., Alonso, S., Rivera, N., Alonso, A., Azkarate, A. y de la Rúa, C. 2007: "Influences of the European Kingdoms of Late Antiquity on the Basque Country", Current Anthropology 48.1, 155-163.

Arce, J. 2011: Esperando a los árabes. Los visigodos en Hispania (507-711), Madrid.

Azkarate, A. 1999: Necrópolis tardoantigua de Aldaieta. Volumen I. Memoria de la excavación e inventario de los hallazgos (Nanclares de Gamboa, Álava), Vitoria- Gasteiz.

Azkarate, A. 2002: "De la tardoantigüedad al medievo cristiano. Una mirada a los estudios arqueológicos sobre el mundo funerario", D. Vaquerizo (ed.), Espacios y usos funerarios en el Occidente romano, Córdoba, 115-140.

Azkarate, A. 2005: "Sobre los orígenes cronológicos de los cementerios cispirenaicos de época tardoantigua", Munibe (Antropología-Arkeologia) 57, 404-417.

Barbiera, I. 2012: Memorie sepolte. Tombe e identità nell'alto medioevo (secoli V-VIII), Roma.

Barroso Cabrera, R. y Morín de Pablos, J. 2007: Excavaciones arqueológicas en Azután, Toledo. Un modelo de evolución en el poblamiento entre los períodos visigodos y emiral, Madrid.

Bentley, R. A. 2006: "Strotium Isotopes from the Earth to the Archaeological Skeleton: A review", 
Journal of Archaeological Method and Theory 13.3, 135-187.

Binford, L. R. 2011: "Las prácticas funerarias: su estado y potencial”, Pyrenae 42.1, 11-47.

Brather, S. 2002: "Ethnic Identities as constructions of Archaeology", A. Gillett (ed.), On Barbarian Identity. Critical Approaches to Ethnicity in Early Middle Ages, Turhnout, 149-175.

Brethell, R., Evans, J., Marzinzik S., Lamb A. y Montgomery, J. 2012: “'Impious Easterners': Can Oxygen and Strontium Isotopes Serve as indictors of provenance in Early Medieval European cemetery populations?", European Journal of Archaeology 15.1, 117-145.

Carver, M. 2009: Wasperon: A Roman, British and Anglo-Saxon Community in Central England, London.

Castellanos, S. 2007: Los godos y la cruz. Recaredo y la unidad de Spania, Madrid.

Chavarria Arnau, A. 2006: "Aristocracias tardoantiguas y cristianización del territorio (siglos IV-V): ¿otro mito historiográfico?', Rivista di Archeologia Cristiana 82, 201-230.

Chavarria Arnau, A. 2009: Archeologia delle chiese. Dalle origini all'anno Mille, Roma.

Collins, R. 2005: La España visigoda, 409-711, Barcelona.

Contreras Martínez, M. 2006: "Evolución del ritual funerario entre los siglos. VI y VIII d.C. en el asentamiento de Gózquez de Arriba (San Martín de la Vega, Madrid), J. López Quiroga, A. M. Martínez Tejera y J. Morín de Pablos (eds.), Gallia e Hispania en el contexto de la presencia 'germánica' (siglos. V-VII). Balance y perspectivas, Oxford, 273-288.

Curta, F. 2005: Borders, barriers and ethnogenesis: Frontiers in Late Antiquity and the Middle Ages, Turnhout.

Curta, F. 2007: "Some remarks on ethnicity on medieval archaeology", Early Medieval Europe 15.2, 159-185.

DeNiro, M. I. 1987: "Stable isotope and Archaeology", American Scientist 75, 182-190.

Dyer, C. 1991: Niveles de vida en la Baja Edad Media. Cambios sociales en Inglaterra, c. 1200-1500, Barcelona.

Eckardt, H., Chenery, C., Booth, P., Evans, J. A., Lamb, A. y Müldner G., 2009: "Oxygen and strotium isotope evidence for mobility in Roman Winchester", Journal of Archaeological Science 36, 2816-2825.

Fernández Crespo, T. 2011: Estudio arqueo-antropológico de las inhumaciones tardorromanas, tardoantiguas y altomedievales de la necrópolis de
San Martín de Dulantzi (Álava), informe técnico inédito depositado en la Diputación Foral de Álava, Vitoria-Gasteiz.

Fernández Domínguez, E, Gamba, C., Arroyo-Pardo, E., Vigil-Escalera, A., Vírseda L. y Barrio Caballero P. A., 2009: "Resultados del análisis de 30 muestras de dientes de tres necrópolis altomedievales en la C.A.M.", Actas de las Cuartas Jornadas de Patrimonio Arqueológico en la Comunidad de Madrid (M.A.R., Alcalá de Henares, 21-23 noviembre 2007), Madrid, 301-305.

Fernández Domínguez, E., Gamba, C., Arroyo-Pardo, E., Vigil-Escalera, A., Vírseda L. y Barrio P. A. 2009: "Aplicaciones del ADN antiguo en Arqueología. La nueva 'Arqueología molecular'”, Actas de las Cuartas Jornadas de Patrimonio Arqueológico en la Comunidad de Madrid. Madrid, Madrid, 115-23.

Fernández Götz, M. A. y Ruiz Zapatero G., 2011: "Hacia una Arqueología de la Identidad", Trabajos de Prehistoria 68 (2), 219-236.

Fuller, B. T., Márquez-Grant, N. y Richards, M. P. 2010: "Investigation of diachronic dietary patterns on the islands of Ibiza and Formentera, Spain: Evidence from Carbon and Nitrogen stable isotope ratio analysis", American Journal of Physical Anthropology 143.2, 515-522.

Gillet, A. 2006: "Ethnogenesis: a contested model of Early Medieval Europe", History Compass 4.2, 241-260.

Godoy Fernández, C. 1995: Arqueología y liturgia. Iglesias hispánicas (siglos IV al VIII), Barcelona.

Gurruchaga, I. 1951: "Localización de algunas ciudades várdulas citadas por Mela y Ptolomeo", Boletín del Instituto Americano de Estudios Vascos 7, 222-231.

Hakenbeck, S. E. 2007: "Situational ethnicity and nested identities: new approaches to an old problem", Anglo-Saxon Studies in Archaeology and History 14, 19-27.

Hakenbeck, S. 2008: "Migration on Archaeology: Are we nearly there yet?', Archaeological Review from Cambridge 23.2, 9-26.

Hakenbeck, S. 2011: Local, regional and etnic identities in early medieval cemeteries in Bavaria, Firenze.

Hakenbeck, S., McManus, E., Geisler, H., Grupe, G. y O'Connell, T. 2010: "Diet and Mobility in Early Medieval Bavaria: A study of Carbon and Nitrogen Stable Isotopes", American Journal of Physical Anthropology 143.2, 235-249.

Halsall, G. 2007: Barbarian migrations and the Roman West, 376-568, Cambridge. 
Halsall, G. 2009: Cemeteries and society in Merovingian Gaul. Selected studies in History and Archaeology, 1992-2009, Leiden.

Hamerow, H. 1997: "Migration theory and the anglosaxon identity crisis", J. Chapman y H. Hamerow (eds.), Migrations and invasions in archaeological explanation, Oxford, 33-44.

Härke, H. 2007: 'Ethnicity, 'Race' and migration in mortuary archaeology: an attempt at a short answer", Anglo-Saxon Studies in Archaeology and History 14, 12-18.

Härke, H. 2011: "Anglo-Saxon Inmigration and Ethnogenesis", Medieval Archaeology 55, 1- 28.

Heather, P. 2010: Emperadores y bárbaros, El primer milenio de la Historia de Europa, Barcelona.

Hedges, R. 2011: "Anglo-Saxon migration and the molecular evidence", H. Hamerow, D. A. Hinton y S. Crawford (eds.), The Oxford handbook of Anglo-Saxon Archaeology, Oxford, 79-90.

Iriarte Kortazar, A. 1998: "La necrópolis de San Pelayo (Alegría-Dulantzi, Álava) y la cuestión de la fecha de inicio de las necrópolis de tipo merovingio en Álava", Cuadernos de Arqueología Universidad de Navarra 6, 139-163.

James E. 2011: I barbari, Bologna.

Johnson, M. 2010: Archaeological Theory. An Introduction, London.

Jones S., 1997: The Archaeology of Ethnicity. Constructing identities in the past and the present, New York.

Knudson, K. J., Williams, H. M., Buikstra, J. E., Tomczak, P. D., Gordon, G. W. y Anbar, A. D., 2010: "Introducing ${ }^{88 / 86} \mathrm{Sr}$ analysis in archaeology: a demonstration of the utility of strontium isotope fractionation in paleodietary studies", Journal of Archaeological Science 37, 2352-2364.

Kulikowski, M. 2005: "Etnicity, Rulership and Early Medieval Frontiers", F. Curta (ed.), Borders, barriers and ethnogenesis. Frontiers in Late Antiquity and the Middle Ages, Turnhout, 247-254.

López Quiroga J. 2010: Arqueología del mundo funerario en la Península Ibérica (siglos V al X), Madrid.

Loza Uriarte, M. y Niso Lorenzo J. 2011: "Resultados preliminares de la intervención arqueológica de San Martín de Dulantzi (Alegría-Dulantzi, Álava)", J. A. Quirós (ed.), Vasconia en la Alta Edad Media 450-1000, poderes y comunidades rurales en el Norte Peninsular, Bilbao, 235-246.

Loza Uriarte M. y Niso Lorenzo J. 2012: "Yacimiento de San Martín de Dulantzi”, Arkeoikuska 2011, 35-37.

Lubritto, C., Ricci, R., Sirignano, C., Rubino, M. y Quirós Castillo, J. A. 2012: "Paleodiet and social analysis of Basque rural communities between early and late medieval period", en prensa.

Malainey, M. E. 2011: A consumer's guide to archaeological science: analytical techniques. Springer, New York.

Mendizabal Gorostizu-Orkaiztegi A. 2011: "Estudio antropológico y patológico de cementerios altomedievales en el País Vasco. Los casos del despoblado de Aistra y el Castillo de Treviño", Munibe (Antropologia-Arkeologia) 62, 403-421.

Montgomery, J. Evans, J. A., Powlesland, D. y Roberts C. A., 2005: "Continuity and colonization in Anglo-Saxon England? Isotope evidence for mobility, subsistence practice and status at West Heslerton", American Journal of Physical Anthropology 126, 123-138.

Morín de Pablos J., Barroso Cabrera R., 2008: "El mundo funerario: de las necrópolis tardorromanas a los cementerios hispanovisigodos en el oeste peninsular", Zona Arqueológica 11, 148-180.

Müldner, G., Montgomery, J., Cook, G., Ellm, R., Gledhill, A. y Lowe C., 2009: "Isotopes and individuals: diet and mobility amount the medieval Bishops of Whithron", Antiquity 83, 1119-1113.

Mundee, M., 2010, Exploring Diet and Society in Medieval Spain: New Approaches Using Stable Isotope Analysis, Doctoral thesis, Durham University.

Ortega, L. A., Guede, I., Aranguren, I., Zuluaga, M. C., Alonso, A., Murelaga, X., Niso, J., Loza M. y Quirós J. A., 2012: "Estudio isotópico del Sr en restos óseos del cementerio altomedieval de $\mathrm{Du}$ lantzi (Alegría-Dulantzi, Álava)", Macla 16, $42-43$.

Ortega, L. A., Guede, I., Zuluaga, M. C., Alonso A., Murelaga, X., Niso, J., Loza, M. y Quirós, J. A., 2012: "Strontium isotopes of human remains from the San Martín de Dulantzi graveyard (AlegríaDulantzi, Álava) to infer population mobility in the Early Middle Ages, Quaternary International 303, 54-63.

Pöhl, W. 1998a: "Introduction: strategies of distinction”, en W. Pöhl, H. Reimitz (eds.), Strategies of distinction. The construction of Ethnic Communities, 300-800, Leiden, 1-15.

Pöhl, W. 1998b: "Telling the difference: signs of ethnic identity", W. Pöhl y H. Reimitz (eds.), Strategies of distinction. The construction of Ethnic Communities, 300-800, Leiden, 17-69.

Pollard, A. M. y Heron, C., 2008: Archaeological Chemistry, Cambridge.

Prevedorou, E., Díaz-Zorita Bonilla, M., Romero, A., Buikstra, J. E., Miguel Ibáñez, M. Paz y Knud- 
son J. J., 2010: "Residential mobility and dental decoration in Early Medieval Spain: results from the eighth century site of Plaza del Castillo, Pamplona”, Dental Anthropology 23.2, 42-52.

Quirós Castillo, J. A. 2011a: "Los paisajes altomedievales de Vasconia, 500-900. De la desarticulación territorial a la emergencia de los condados", J. A. Quirós Castillo (ed.), Vasconia en la Alta Edad Media, 450-1000. Poderes y comunidades rurales en el Norte Peninsular, Bilbao, 29-54.

Quirós Castillo, J. A. 2011b: "Dossier Archaeology and ethnicity. Reassessing the 'Visigothic necropoleis"”, Arqueología y Territorio Medieval 18, 9-54.

Quirós Castillo, J. A. 2012: "Los comportamientos alimentarios del campesinado medieval en el País Vasco y su entorno (siglos VIII-XIV)", Historia Agraria 59, 13-41.

Quirós Castillo, J. A., Ricci, P. y Lubritto, C., 2012: "Paleodieta e società rurali altomedievali dei Paesi Baschi alla luce dei marcatori isotopici di C e N", Archeologia Medievale XXXIX, 87-92.

Quirós Castillo, J. A. y Vigil-Escalera Guirado, A., 2011: "Dove sono i Visigoti? Cimiteri e villaggi nella Spagna settentrionale dei secoli VI e VII", Convengo Internazionale di Studi Archeologia e Storia delle migrazioni: Europa, Italia, Mediterraneo fra tarda età romana e alto medioevo, Cimitile, 159-181.

Ripoll López, G., 1994: "La necrópolis visigoda de El Carpio de Tajo. Una nueva lectura a partir de la topocronología y los adornos personales", Butlletí de la Reial Acadèmia Catalana de Belles Arts de Sant Jordi VII-VIII, 187-250.

Ripoll López, G. 2007: "Las necrópolis visigodas. Reflexiones en torno al problema de la identificación del asentamiento visigodo en Occidente según los materiales arqueológicos", Hispania Gothorum. San Ildefonso y el reino visigodo de Toledo, Toledo, 59-74.

Ripoll, G., Carrero, E., Rico, D., Tuset, F., Velázquez, I., López Battle, A., Mas, C., Valls, M. y Cau, M. A., 2012: "La arquitectura religiosa hispánica del siglo IV al X y el proyecto del Corpus Architecturae Religiosae Europeae-CARE-Hispania", Hortus Artium Medievalium 18.1, 45-73.

Roig, J. 2009: “Asentamientos rurales y poblados tardoantiguos y altomedievales en Cataluña (siglos VI al X)", J. A. Quirós Castillo (ed.), The Archaeology of Early Medieval Villages in Europe, Bilbao, 207-251.

Roig, J. y Coll, J. M., 2011: "Esquelets humans en sitges, pous i abocadors als assentaments rurals $\mathrm{i}$ vilatges de l'antiguitat tardana de Catalunya (segles V-VIII). Evidències arqueològiques de la presència d'escalus i serfs", IV Congrés d'Arqueologia Medieval i Moderna a Catalunya, Barcelona, 75-82.

Schutlowski, H., Hermann, B., Wiedemann, F., Bocherens, H. y Grupe G. 1999: "Diet, Status and Decomposition at Weingarten: Trace Element and Isotope analyses on Early Mediaeval skeletal material", Journal of Archaeological Science 26, 675-685.

Schwarcz H. P., 1991: "Some theoretical aspects of isotope paleodiet studies", Journal of Archaeological Science 18, 261-275

Sealy, J. 2001: "Body tissue chemistry and paleodiet", D. R. Brothwell y A. M. Pollard (eds.), Handbook of Archaeological Sciences, London, 269-279.

Utrero Agudo, $\mathbf{M}^{\mathrm{a}}$. A., 2006: Iglesias tardoantiguas y altomedievales en la Península Ibérica. Análisis arqueológico y sistemas de abovedamiento, Madrid.

Valenti, M. 2009: "Ma i 'barbari' sono veramente arrivati in Italia?", G. Volpe y P. Favia (a cura di), V Congresso Nazionale di Archeologia Medievale, Firenze, 25-30.

Vigil-Escalera Guirado, A. 2007: "Granjas y aldeas altomedievales al Norte de Toledo (450- 800 d.C.)", Archivo Español de Arqueología 80, 239-284.

Vigil-Escalera Guirado A., 2013: "Comunidad política aldeana y exclusión. Una revisión de las formas de inhumación altomedievales (siglo V-VIII d.C.)", Reti Medievali Rivista 14(1), 1-42.

Ward-Perkins B., 2005: The fall of Rome and the end of civilization, Oxford.

Recibido: 05-06-2012

Aceptado: 26-09-2012 